\title{
Effects of deformation texture and grain size on corrosion behavior of $\mathrm{Mg}-3 \mathrm{Al}-1 \mathrm{Zn}$ alloy sheets
}

Da-Wei Lia ${ }^{a}$, Hui-Yuan Wanga, Dong-Song Weia, Zheng-Xue Zhao, Yan Liub,*

${ }^{a}$ Key Laboratory of Automobile Materials of Ministry of Education \& School of Materials Science and Engineering, Nanling Campus, Jilin University, No. 5988 Renmin Street, Changchun 130025, PR China; International Center of Future Science, Jilin University, Changchun 130012, PR China

${ }^{\mathrm{b}}$ Key Laboratory of Bionic Engineering (Ministry of Education), Jilin University, Changchun 130025, PR China

\footnotetext{
* Corresponding author at: Key Laboratory of Bionic Engineering (Ministry of Education), Jilin University, Changchun 130025, China.

E-mail address: lyyw@jlu.edu.cn (Y. Liu).
}

Tel: +8643185095760 


\section{Supplementary Information}
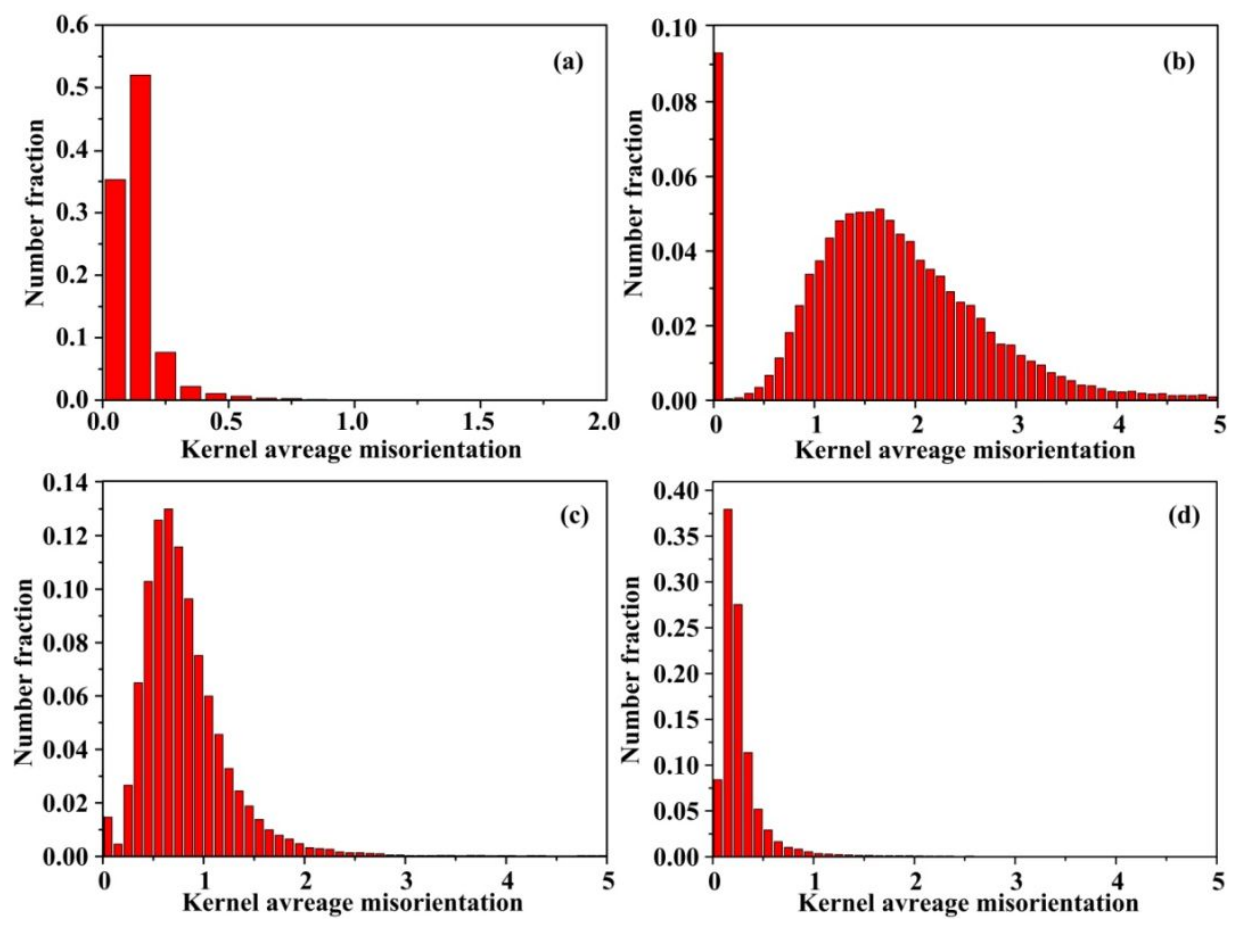

Figure. S1. The corresponding number fraction of KAM (a) as-extruded AZ31 plate after solution treatment, (b) rolling 7 passes and then annealing for $30 \mathrm{~min}$ at (c) $400{ }^{\circ} \mathrm{C}$, (d) $200{ }^{\circ} \mathrm{C}$. 